\title{
Donor Heart Assessment Model
}

\section{ISSN: 2637-8078}

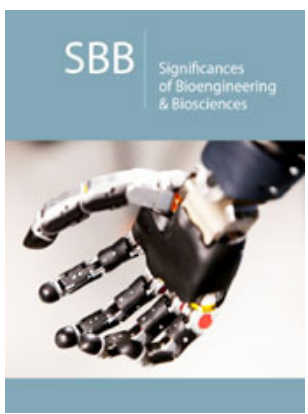

*Corresponding author: Tenchurina EA SP Botkin City Clinical Hospital, Moscow City Coordination Center for Organ Donation, Moscow, Russia

Submission: 眥 October 10, 2020

Published: 眥 October 23, 2020

Volume 4 - Issue 1

How to cite this article: Tenchurina EA* and Minina MG. Donor Heart Assessment Model. Significances Bioeng Biosci.4(1). SBB.000580.2020.

DOI: 10.31031/SBB.2020.04.000580

Copyright@ Tenchurina EA, This article is distributed under the terms of the Creative Commons Attribution 4.0 International License, which permits unrestricted use and redistribution provided that the original author and source are credited.

\section{Tenchurina EA* and Minina MG}

SP Botkin City Clinical Hospital, Moscow City Coordination Center for Organ Donation, Russia

\section{Abstract}

Selection of donor heart-an important step, which affects the success of heart transplantation. Purpose- creating a model for evaluation of a donor's heart, based on donor characteristics.

\section{Materials and Methods}

Data consists of 650 brain dead donors (BDD) in a period from 1st of January 2012 till 31st of December 2017. In model creation, binomial logistic regression used. The dependent variable is a rejection of donor heart and donor characteristics attributed to independent factors. The odds ratios (OR) value determined for each factor, then transformed into points, and the sum of the points is a score of the donor's heart. The given model is validated by choosing 218 donors for the period from 1st of January 2019 till 31st of December 2019.

\section{Results}

Donors characteristics included in the model are age, cause of death (Traumatic brain injury/Stroke), history of Hypertension and Diabetes Mellitus, out (-in) hospital cardiac arrest, cardiac trauma, and HR, MAP, arterial lactate, requirements of norepinephrine before procurement of organs. Based on the average value of the sum of points, 2 groups were identified: donors of low risk ( $\leq 17$ points) and donors of high risk ( $\geq 18$ points). Analysis of the ROC curve showed the properties of the predictive model, AUC0.904, sensitivity-90.2\%, specificity-90.4\%.

\section{Conclusion}

This given model assessing donor hearts accurately reflects the probability of using the heart of the donor for transplantation and forms features for optimal distribution of cardiac transplants, especially from donors of high risk.

Keywords: Model assessment of the heart donor; Donor risk factors for a heart transplant

Abbreviations: OR: Odds Ratio; TBI: Traumatic Brain Injury; HR: Heart Rate; MAP: Mean Arterial Pressure's; DLR: The Donor is at Low Risk; DHR: The Donor is at High Risk; ROC Curve: Receiver Operating Characteristic; AUC: Area Under the ROC Curve

\section{Introduction}

To decide if the donor's heart is suitable for transplantation, specialists must consider donor factors and recipient factors to obtain optimal results. Often, it is difficult subjectively to assess the quality of heart, especially with donors having expanded criteria. Statistic models are used to determine the relationship between initial factors and the final result, for making an objective decision. In such models, the score of the donor's heart, as a rule, is measured by the sum of points, defined by each factor. The most popular model of this kind is the European [1] and a model, created by American researchers using the UNOS database [2]. Improving the assessment of the heart donor condition, as well as the standardization of risk factors, is extremely important for improving the effectiveness of heart transplantation [3].

\section{Materials and Methods}

Data of 650 BDD used, which organs were explanted from $1^{\text {st }}$ of January 2012 till $31^{\text {st }}$ of December 2017. 198 donor's hearts $(30,5 \%)$ were rejected from using in heart transplantation. In the initial stage, the overall analysis showed why the explanted hearts were rejected. Binomial logistic regression was used to estimate the total risk of using the donor heart for transplantation, the ultimate point which was the rejection of the donor's heart, and independent factors became characteristics of the donor-Age, Sex, Cause of death, Hypertension, Diabetes Mellitus, Circulatory arrest, cardiac pathologies, and acute cardiac trauma; following indicators were considered in two values (initial medical examination of donor, indicated by number 1 and just before organ harvesting, which is number 2 , respectively)-MAP, HR, Hemoglobin, $\mathrm{pH}$, lactate, Na, glucose, Noradrenaline, creatinine. An 
odds ratio received in the regression model, were converted into points. The score of the donor's heart received by summing points of factors, found in a specific donor. Based on the average value of the sum of points, 2 groups were identified: donors of low risk $(\leq 17$ points) and donors of high risk ( $\geq 18$ points). 218 donors included in this survey to validate the given model for the period from $1^{\text {st }}$ of January till the $31^{\text {st }}$ of December 2019. The verification showed an accurate difference in the overall rate of rejection of donor heart depending on the score of the donor's heart. The processing of the survey was carried out using SPSS 23.0 for Windows.

\section{Discussion and Results}

From 650 BDD, 452 donors $(69,5 \%)$ underwent heart explanation, in $198(30,5 \%)$ cases, the heart did not used for transplantation (Figure 1).

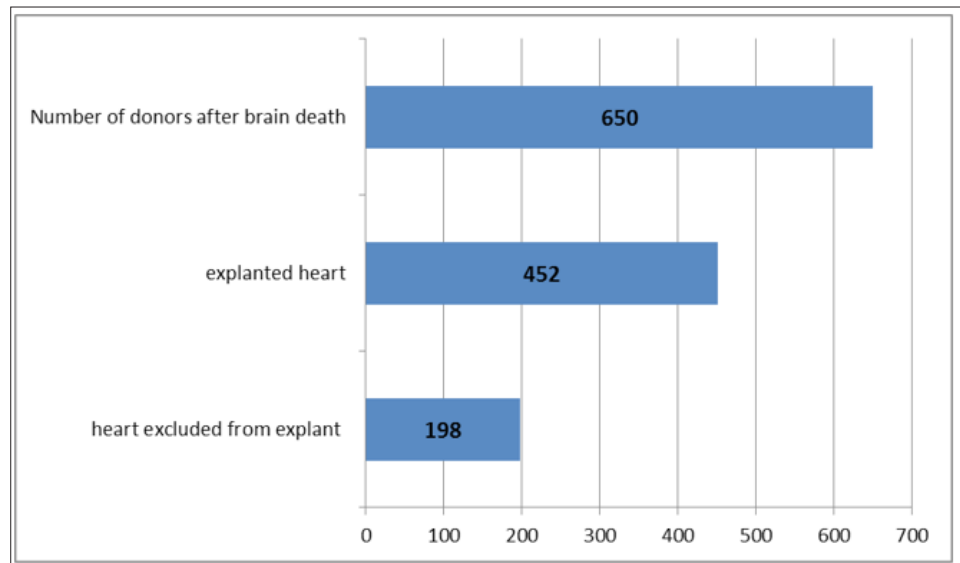

Figure 1: Distribution of BDD, included in the survey.

\section{Analysis of donor factors}

Table 1: Investigated donor factors and the percentage of rejections from the donor's heart.

\begin{tabular}{|c|c|c|c|c|}
\hline Donor Factors & BDD $(n=650)$ & Heart Explanted $(n=452)$ & $\begin{array}{l}\text { Heart not Explanted } \\
\qquad(\mathrm{n}=198)\end{array}$ & $\begin{array}{c}\text { Rejection of a Donor's Heart, } \\
\%\end{array}$ \\
\hline \multicolumn{5}{|c|}{ Age of Donor, Years } \\
\hline $18-30$ & 78 & 67 & 11 & 14,1 \\
\hline $31-40$ & 113 & 96 & 17 & 15,9 \\
\hline $41-50$ & 193 & 139 & 54 & 27,5 \\
\hline $51-60$ & 227 & 133 & 94 & 41,4 \\
\hline $61-69$ & 38 & 16 & 22 & 57,9 \\
\hline $70+$ & 1 & 1 & 0 & 0,0 \\
\hline \multicolumn{5}{|c|}{ Cause of Death } \\
\hline TBI & 239 & 179 & 60 & 25,1 \\
\hline Stroke & 411 & 273 & 138 & 33,6 \\
\hline \multicolumn{5}{|c|}{ Sex } \\
\hline Male & 464 & 329 & 135 & 29,1 \\
\hline Female & 186 & 123 & 63 & 33,9 \\
\hline \multicolumn{5}{|c|}{ Hypertension } \\
\hline Yes & 364 & 231 & 133 & 36,5 \\
\hline No & 286 & 221 & 65 & 22,7 \\
\hline \multicolumn{5}{|c|}{ Diabetes Mellitus } \\
\hline Yes & 70 & 39 & 31 & 44,3 \\
\hline No & 580 & 413 & 167 & 28,7 \\
\hline
\end{tabular}




\begin{tabular}{|c|c|c|c|c|}
\hline \multicolumn{5}{|c|}{ MAP, mm Hg } \\
\hline$<=60$ & 46 & 31 & 15 & 32,6 \\
\hline$>=61$ & 604 & 421 & 183 & 30,3 \\
\hline \multicolumn{5}{|c|}{$\mathrm{pH}, \mathrm{mmol} / \mathbf{l}$} \\
\hline$\leq 7,0-7,2$ & 31 & 21 & 10 & 32,3 \\
\hline$\geq 7,3$ & 582 & 414 & 168 & 28,9 \\
\hline No data & 37 & 17 & 20 & \\
\hline \multicolumn{5}{|c|}{ Lactate, $\mathbf{m m o l} / \mathbf{l}$} \\
\hline $0,1-2,2$ & 229 & 165 & 64 & 27,9 \\
\hline $2,3-5,9$ & 179 & 132 & 47 & 26,3 \\
\hline $6,0-13,0$ & 40 & 25 & 15 & 37,5 \\
\hline$>13,0$ & 5 & 3 & 2 & 40,0 \\
\hline No data & 197 & 127 & 70 & \\
\hline \multicolumn{5}{|c|}{$\mathrm{Na}, \mathrm{mmol} / \mathrm{l}$} \\
\hline $120-135$ & 66 & 47 & 19 & 28,8 \\
\hline $136-145$ & 293 & 204 & 89 & 30,4 \\
\hline $146-155$ & 133 & 94 & 39 & 29,3 \\
\hline$\geq 156$ & 122 & 90 & 32 & 26,2 \\
\hline No data & 36 & 17 & 19 & \\
\hline \multicolumn{5}{|c|}{ Glucose, mmol/l } \\
\hline$\leq 8,3$ & 213 & 153 & 60 & 28,2 \\
\hline $8,4-10,9$ & 161 & 118 & 43 & 26,7 \\
\hline$\geq 10,9$ & 221 & 149 & 72 & 32,6 \\
\hline No data & 55 & 32 & 23 & \\
\hline \multicolumn{5}{|c|}{ Noradrenaline, ng/kg/min } \\
\hline 100 & 44 & 35 & 9 & 20,6 \\
\hline $100-400$ & 182 & 129 & 53 & 29,1 \\
\hline $401-800$ & 166 & 119 & 47 & 28,3 \\
\hline$>800$ & 111 & 72 & 39 & 35,2 \\
\hline No data & 11 & 7 & 4 & \\
\hline
\end{tabular}

In (Table 1) total rejections of a donor's heart (\%) are presented, depending on the presence/absence of the donor factor. The analysis demonstrates that the percentage of rejection is direct proportional to the age of the donor. In the group «41-50» years, the rejection rate was 27,5 , in the group «51-60»-41,4, while in the group of «60+» years, it increased to $57,9 \%$. Despite the expansion of donor criteria, rejection rate for donors died due to stroke still exceed those for donors who died from craniocerebral trauma, 33,6 vs $25,1 \%$. Donors presenting with concomitant diseases such as Hypertension and Diabetes Mellitus demonstrate a significant impact on the percentage of rejection. MAP did not significantly impact rejection rate, while the key indicator of homeostasis-blood lactate, was proportional to the increased rejection rate. Donors with blood lactate in the range of $6-13 \mathrm{mmol} / \mathrm{l}$ (more than normal level in 3-6 times) heart refusals consisted 37,5\%. pH level did not influence on the total sum of refusals of the donor's heart. Rates of rejection at low and normal $\mathrm{pH}$ are quite comparable, 32,3 vs 28,9 respectively. There was not a significant difference in the number of rejections of the donor's heart depending on $\mathrm{Na}$, at both normal and high values, the average rejection rate was $28,7 \%$. As expected, hearts refusals increased, in association with high doses of Noradrenaline requirement, consisting at its minimal value (100ng/kg/min) $20,6 \%$ versus $35,2 \%$ when infusion rate was more than $800 \mathrm{ng} / \mathrm{kg} / \mathrm{min}$. 
Multivariate regression model for evaluating a donor's heart

Table 2: Binomial logistic regression. Source: *Maximum-63 points, minimum-10 points. Donor at low risk $\leq 17$ points, donor at high risk $\geq 18$ points. ${ }^{* *}$ Circulatory arrest during pre-hospital or in-hospital phases. ${ }^{* * *}$ IHD, cardiac arrhythmia, cardiovascular diseases, and implantation of heart valves.

\begin{tabular}{|c|c|c|c|c|}
\hline Factors & OR & Confidence Interval & Points* & $\mathbf{p}$ \\
\hline \multicolumn{5}{|c|}{ Age } \\
\hline$<45$ & 0,35 & $0,237-0,504$ & 1 & \multirow{4}{*}{$<0,0001$} \\
\hline $45-54$ & 1,22 & $0,86-1,74$ & 1 & \\
\hline $55-59$ & 1,85 & $1,24-2,77$ & 2 & \\
\hline$>60$ & 2,81 & $0,86-1,74$ & 3 & \\
\hline \multicolumn{5}{|c|}{ Cause of Death } \\
\hline Stroke & 1,51 & $1,06-2,16$ & 2 & \multirow{2}{*}{0,024} \\
\hline TBI & 0,66 & $0,46-0,95$ & 1 & \\
\hline \multicolumn{5}{|c|}{$\mathbf{H b}$} \\
\hline Yes & 1,96 & $1,39-2,8$ & 2 & \multirow{2}{*}{0,001} \\
\hline No & 0,506 & $0,36-0,72$ & 1 & \\
\hline \multicolumn{5}{|c|}{ Diabetes Mellitus } \\
\hline Yes & 1,97 & $1,19-3,26$ & 2 & \multirow{2}{*}{0,009} \\
\hline No & 0,51 & $0,31-0,843$ & 1 & \\
\hline \multicolumn{5}{|c|}{ Circulatory Arrest** } \\
\hline Yes & 23,99 & $3,05-188,72$ & 24 & \multirow{2}{*}{$<0,0001$} \\
\hline No & 0,042 & $0,005-0,33$ & 1 & \\
\hline \multicolumn{5}{|c|}{ Cardiovascular Diseases (CVD) and Cardiac Injuries $* * *$} \\
\hline Yes & 14,61 & $6,39-33,43$ & 15 & \multirow{2}{*}{$<0,0001$} \\
\hline No & 0,68 & $0,30-0,157$ & 1 & \\
\hline \multicolumn{5}{|c|}{ HR 2, bpm } \\
\hline$<60$ & 7,45 & $0,77-72,1$ & 7 & \multirow{3}{*}{$<0,0001$} \\
\hline $60-90$ & 0,51 & $0,36-0,74$ & 1 & \\
\hline$>90$ & 1,83 & $1,27-2,63$ & 2 & \\
\hline \multicolumn{5}{|c|}{ MAP 2, mm Hg } \\
\hline$<70$ & 0,57 & $0,06-5,12$ & 1 & \multirow{4}{*}{$<0,0001$} \\
\hline $70-110$ & 0,63 & $0,44-0,91$ & 1 & \\
\hline $110-150$ & 1,42 & $0,97-2,10$ & 1 & \\
\hline$>150$ & 3,03 & $1,11-8,25$ & 3 & \\
\hline \multicolumn{5}{|c|}{ Lactate $2, \mathrm{mmol} / \mathrm{l}$} \\
\hline$<2$ & 0,58 & $0,37-0,89$ & 1 & \multirow{2}{*}{$0,060^{*}$} \\
\hline$>2$ & 1,72 & $1,13-2,64$ & 2 & \\
\hline \multicolumn{5}{|c|}{ Noradrenaline $2, \mathrm{ng} / \mathrm{kg} / \mathrm{min}$} \\
\hline$<100$ & 1,23 & $0,85-1,77$ & 1 & \multirow{4}{*}{$0,061^{* *}$} \\
\hline $100-600$ & 0,785 & $0,56-1,10$ & 1 & \\
\hline $600-1000$ & 0,813 & $0,45-1,46$ & 1 & \\
\hline$>1000$ & 2,615 & $1,09-6,26$ & 3 & \\
\hline
\end{tabular}


(Table 2) presents donor's factors which influence on heart refusal showed statistical significance. Factors are not demonstrating significant impact on rejection decision, were excluded from the model such as sex, as well as MAP, HR, Haemoglobin, Ph, lactate, $\mathrm{Na}$, glucose and creatinine, noradrenaline, documented during the initial examination of donor. Two factors showed a tendency of reliability, lactate $2(\mathbf{p}=0,060)$ and noradrenaline $2(0,061)$, and that made it possible to include them in the regression model. OR value determined for each factor converted into the points. Obtained OR reflect the probability of donation, depending on the presence/ absence of any of the donor factors compared to the basic values of donor factors. Thus, for example, the chance of heart rejection for transplantation of a 56 years old donor was 1,85 times more, than 46 years old donor, in which OR value was 1 point. The total sum of points consists the final score of the donor's heart. Examples of calculating of donor's heart score are presented (Table 3). A donor 1 , aged 46 years, receiving 19 points, is a high-risk donor, and a donor aged 56 years, with no concomitant diseases, gains a final score of 13 points, in spite of his age. The rate of rejection of donors, collecting 19 and 13 points, was $100 \%$ vs 2,8\%, respectively. The functionality of the proposed model was evaluated using a donor validation pool for the period from January 1 to December 31, 2019. The proportion (\%) of refusals from a donor's heart increased significantly, with the total achievement of 18 points or more by donors (Figure 2). Failures for the DLR were $4.1 \%$, for the DHR $78.6 \%$, the difference is statistically significant $(\mathrm{p}<0.0001)$, Pearson's $\mathrm{X}^{2}$ is 130.9 .

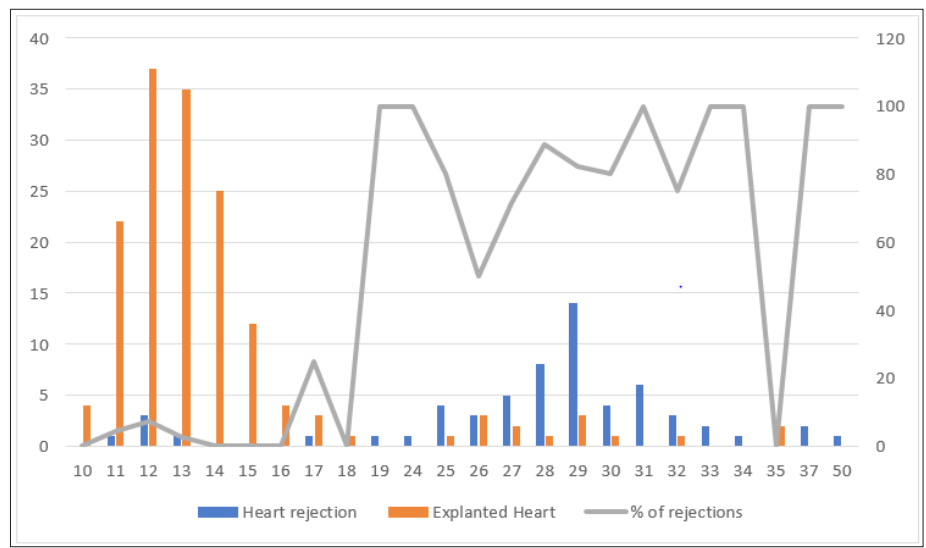

Figure 2: Donor heart score in points and rejection rate (\%).

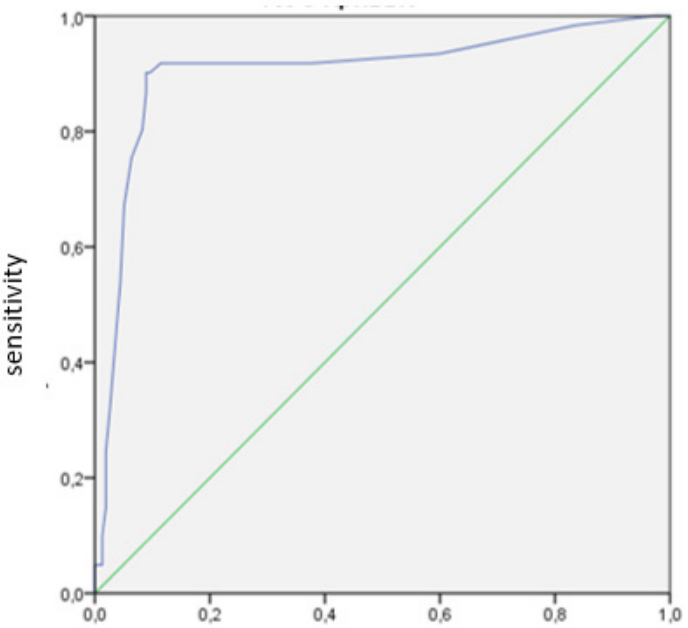

Figure 3: ROC curve.

Using the donor validation pool the classification ability of the donor assessment model was analyzed based on the construction of the ROC curve [4]. The "predictor" role was the total score of the heart donor, and the "response" role was the rejection of the donor's heart for transplantation. During the analysis of the ROC curve, we obtained indicators that characterize the quality of the prognostic model for evaluating a donor heart, such as AUC-0.904, sensitivity-90.2\%, specificity-90.4\%. Thus, according to AUC-0.904, we can judge the excellent quality of the model, and the sensitivity and specificity indicators show high values (Figure 3). The cut-off point that separates the high-risk and low-risk donor groups is 17.5, which almost corresponds to the 17-point value that was verified during the construction of the prognostic model for evaluating a donor's heart. 


\section{Conclusion}

Donor risk factors were used to estimate heart donors in this scientific research. The regression model reflects the evolution in the assessment of heart donors, monitored in Moscow for the past 10 years. A scoring system was developed relying on evidencebased data of heart donor rejections to prevent the subjective estimation of each donor factor, associated with the risk of failed transplantation. The regression model can be used at the early steps of the evaluation of heart donors as a tool detecting donors at high risk. Undoubtedly, heart transplantation specialists decide if the donor's heart is suitable for transplantation, based on the results of invasive modern diagnostics as needed. However, at the initial stage of selection of a donor heart for transplantation, a simple and affordable tool is needed that allows you to quickly provide objective information about the donor to all interested transplant centers for pre-selection of the recipient.

\section{References}

1. Smits JM, De Pauw M, De Vries E, Axel O Rahmel, Bruno M Meiser, et al. (2012) Donor scoring system for heart transplantation and the impact on patient survival. J Heart Lung Transplant 31(4): 387-397.

2. Weiss ES, Allen JG, Kilic A, Arman Kilic, Stuart D Russell, William A Baumgartner, et al. Development of a quantitative donor risk index to predict short-term mortality in orthotopic heart transplantation. J Heart Lung Transplant 31(3): 266-273.

3. Richard Dorent, Estelle Gandjbakhch, Céline Goéminne, Fabrice Ivanes, Laurent Sebbag, et al. (2018) Assessment of potential heart donors: A statement from the French heart transplant community. Archives of Cardiovascular Diseases 111(2): 126-139.

4. Grigoriev SG, Lobzin YV Skripchenko NV (2016) The role and place of logistic regression and ROC analysis in solving medical diagnostic task. J of Infectology 8(4): 36-45. 